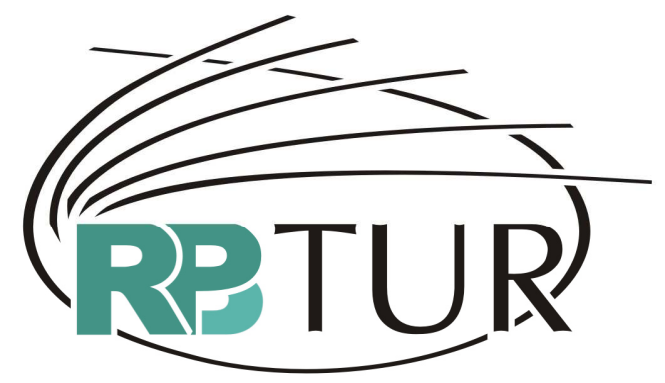

REVISTA BRASILEIRA DE PESQUISA EM TURISMO

\title{
INCLUSÃO SOCIAL, CIDADANIA E TURISMO - UMA INVESTIGAÇÃO SOBRE A EXISTÊNCIA DE SERVIÇOS ADAPTADOS ÀS PESSOAS COM NECESSIDADES ESPECIAIS NOS MEIOS DE HOSPEDAGEM DA REGIÃO METROPOLITANA DE CURITIBA
}

\author{
SOCIAL INCLUSION, CITIZENSHIP AND TOURISM. A SURVEY \\ ON SERVICES SUITABLE TO HANDICAPPED PEOPLE IN \\ HOTELS AT CURITIBA (PARANA, BRAZIL) AND \\ SORROUNDINGS
}

Elizabete Sayuri Kushano ${ }^{1}$ Wolney Gomes Almeida ${ }^{2}$

\begin{abstract}
RESUMO: O presente trabalho reflete sobre a importância da inclusão social no Turismo, especialmente junto às pessoas com necessidades especiais. Aborda o conceito de inclusão social e o direito do exercício da cidadania. Como procedimento metodológico utilizou-se de uma busca em todos os sites oficiais dos meios de hospedagem da Região Metropolitana de Curitiba (RMC) com o intuito de verificar se em tais há adequações (instalações, equipamentos, serviços etc.) para o hóspede com necessidades especiais, bem como investiga (e/ou confirma), por meio de entrevista por telefone, quantas unidades habitacionais adaptadas existem no meio de hospedagem e qual(is) necessidade(s) especial(is) é (são) atendida(s). Foram identificados 115 meios de hospedagem na RMC com site em funcionamento no período da pesquisa. Desses, 25 informam ter unidades habitacionais adaptadas (UHs), totalizando 37 UHs em toda a RMC. Porém, todas são direcionadas para cadeirantes. Raros meios de hospedagem possuem informação em braile e nenhum possui atendimento em língua de sinais. A inclusão social e cidadania refletem em expor empresas socialmente responsáveis. Seja pelo caráter da filosofia da própria empresa, ou mesmo para cumprir determinada legislação, como também para assegurar uma boa imagem perante a sociedade, o fato é que ter produtos e serviços que abarquem a inclusão de pessoas com necessidades especiais está, felizmente, sendo menos incomum.
\end{abstract}

Palavras-chave: Turismo. Inclusão social. Pessoas com necessidades especiais. Surdos.

ABSTRACT: The objective of this job is to focus in the hospitality in a very specific community, making a big emphasis in people with disabilities, finding the way to service our community of the city the Curitiba. Its very important for them to become better citizens, taking advantage of the metropolitan public access like Institutitions, medical and non medical supplies,

\footnotetext{
${ }^{1}$ Bacharel em Turismo pela Universidade Federal do Paraná. Especialista em Turismo e Meio Ambiente pela Faculdade Estadual de Ciências e Letras de Campo Mourão. Mestranda em Cultura e Turismo pela Universidade Estadual de Santa Cruz. Bolsista CAPES. Email:xsayurix@gmail.com

2 Bacharel em Comunicação Social pela Universidade Estadual de Santa Cruz. Intérprete de Língua Brasileira de Sinais reconhecido pelo MEC. Mestrando em Cultura e Turismo pela Universidade Estadual de Santa Cruz. Bolsista FAPESB.E-mail: wolney_22@yahoo.com.br
} 
ALMEIDA, Wolney Gomes; KUSHANO, Elizabete Sayuri. Inclusão social, cidadania e Turismo: uma investigação sobre a existência de serviços adaptados às pessoas com necessidades especiais nos meios de hospedagem da região metropolitana de Curitiba. Revista Brasileira de Pesquisa em Turismo. v. 2, n. 4, p. 88-101, dez. 2008.

ISSN: $1982-6125$

customer service, etc. I am looking forward to put our creativity to work using marketing over the phone and phone interview to find the real needs of people who are looking for place to stay, including those people with hearing impediment or TDD system. Hosting anybody with any special circumstances or disabilities. During past interviews over the phone, we found out that we have 115 hosted places for people to stay with RMC, transforming 25 units (Uhs) making a total of 37 in all the RMC. Not too many hosting places have signals and guide system for people with special disabilities, or providing them with the right information. We have to work in making the companies aware and directly social responsible to keep and obey the law and keep a great image and example to our community where we live, providing service and solving most their needs, making them very happy and part of our community RMC.

Key words: Tourism. Social inclusion. Handicapped. Deaf.

\section{O que a inclusão social inclui (e exclui)}

O conceito de inclusão social, nas palavras do presidente do Banco Mundial, Paul Wolfowitz, é trazer as pessoas para uma sociedade da qual elas nunca fizeram parte até então. Segundo ele, a meta da Instituição é de reduzir as disparidades através das fronteiras e dentro dos países, integrarem cada vez mais pessoas à economia, promovendo acesso eqüitativo aos benefícios do desenvolvimento, independentemente da nacionalidade, raça ou gênero (BAVA, 2003).

O conceito de inclusão social nasce com seu par antitético, o de exclusão social. Ambos tratam de múltiplos fenômenos relacionados com a questão da pobreza. Ambos não possuem historicidade, assim como os conceitos de qualidade de vida ou de desenvolvimento sustentável. O conceito de exclusão social pretende ser mais abrangente que o conceito de pobreza, ainda que 0 inclua. Mas para que servem?

Tanto exclusão social como inclusão social não são conceitos analíticos. Estes são conceitos políticos, que foram introduzidos por motivos políticos. O conceito original do qual derivam estes outros é o da pobreza, que aparentemente foi considerado muito carregado por políticos que desejavam invisibilizar este fenômeno de produção da pobreza. Como os conceitos de exclusão social e inclusão social são abrangentes e envolvem vários tipos de fenômenos, sua utilização acaba por deslocar do centro do debate a questão da pobreza (BAVA, 2003, p. 12). 
A utilização deste conceito de inclusão social, pelo seu caráter mais abrangente, permite, por exemplo, a apresentação de resultados positivos da ação dos governos e das agências multilaterais, quando identifica a redução nas taxas de mortalidade infantil ou o aumento da esperança de vida das pessoas como indicadores do progresso. É verdade que estes indicadores têm melhorado em quase toda parte, até pelos avanços da ciência médica e de medicamentos que não existiam no passado. O conceito de inclusão social, no entanto, não fala de muitas coisas: do aumento da desigualdade, oculta o fato de que enfrentar a questão da pobreza requer que uma parcela da sociedade deixe de se apropriar do produto social como o faz hoje, não identifica a pobreza como uma construção histórica, o produto de políticas públicas, enfim, este conceito opera como o conceito de desenvolvimento: é um ponto de chegada, um mito; se anuncia na contramão dos processos sociais concretos.

O mito da inclusão social sustenta sua legitimidade enquanto discurso ideológico pela implementação das políticas compensatórias. Alimenta-se dos cases de sucesso que são amplamente debatidos nos circuitos de formação de opinião. Não importa quão pequeno seja o grupo de pessoas beneficiadas. Para isso concorrem as premiações de experiências inovadoras em políticas públicas, a promoção dos trabalhos sociais das ONGs, muito da produção universitária. Estas experiências são articuladas por um discurso que as utiliza para comprovar a viabilidade de suas propostas.

Tanto a discussão da exclusão social como a da inclusão social se centram na dimensão dos indivíduos. Trata-se de buscar a inclusão de indivíduos. Dissociadas das políticas macro-econômicas, estas estratégias focalizam o indivíduo e propõem soluções individuais como caminho da superação da pobreza. A dimensão do coletivo, da sociedade, das políticas públicas, dos distintos interesses dos grupos e classes sociais, o espaço público, a política, tudo isso é suprimido deste discurso.

O núcleo duro desta discussão, portanto, é a questão das políticas públicas que geram a pobreza. É frente a elas que se deve desenvolver o 
maior esforço analítico. Trata-se de buscar associar as políticas macroeconômicas aos seus efeitos sociais perversos. Os estudos do Banco Mundial, no entanto, tem partido de uma noção de pobreza que se reduz à privação de renda e capacidade de consumo dos indivíduos e das famílias, ainda que indicadores como esperança de vida, mortalidade infantil e acesso à educação sejam também levados em conta.

E neste sentido uma noção mais abrangente envolve ir além da questão econômica, como um elemento primordial para a inclusão. Como diz Sassaki (1997, p. 3), em seu conceito de inclusão social:

O processo pelo qual a sociedade se adapta para poder incluir, em seus sistemas sociais gerais, pessoas com necessidades especiais e, simultaneamente, estas se preparam para assumir seus papéis na sociedade. A inclusão social constitui, então, um processo bilateral no qual as pessoas, ainda excluídas, e a sociedade buscam, em parceria, equacionar problemas, decidir sobre soluções e efetivar a equiparação de oportunidade para todos.

Neste sentido, a inclusão social é visualizada como sendo o processo mais aperfeiçoado da convivência de alguém, tido como diferente, com os demais membros da sociedade, tidos como supostamente iguais. A sociedade se prepara e se modifica para receber a diferença, em todas as áreas do processo social (educação, saúde, trabalho, assistência social, acessibilidade, lazer, esporte e cultura).

\section{Necessidades especiais $x$ cidadania}

Entender os aspectos sociais, econômicos, culturais e políticos referentes à inclusão de pessoas com necessidades especiais trata-se, nos dias atuais, de reconhecer a alteridade, a diferença, dentro de um ambiente onde a cidadania é o elemento essencial para a efetivação dos direitos e deveres dos membros de uma sociedade. Neste aspecto, entende-se a inclusão social como cidadania, como participação na condição de cidadão na sociedade com os mesmos direitos e deveres dos demais membros. 
Em se tratando de uma sociedade capitalista, a cidadania é compreendida pelos direitos civis (referentes à liberdade individual), políticos (a participação no exercício do poder político através da representação ou da participação) e sociais (compreendendo o bem-estar do indivíduo, o direito à segurança, ao trabalho, ao lazer, à educação, à saúde, entre outros) considerando ainda a ordem simbólica (crenças, valores, significações socialmente estabelecidas e aceitas mediando o indivíduo e o Estado).

Destacando que o modelo de cidadania varia de uma sociedade para outra, esta vai refletir as condições econômicas, políticas, sociais e culturais das sociedades em um determinado contexto. Daí o surgimento do confronto entre os grupos sociais na busca por seus direitos (OGs, ONGs e movimentos sociais).

Ao surgimento desses movimentos sociais, acentuados após a II Guerra Mundial, que os portadores de deficiências passam a ser reconhecidos também como sujeitos de direitos, principalmente com o programa de Ação Mundial para deficientes proposto pela ONU (1982) quando declara que o meio determina o efeito de uma deficiência ou de uma incapacidade de uma pessoa quando esta é relegada à invalidez, quando Ihe são negadas as oportunidades, inclusive aos aspectos fundamentais como a vida familiar, a educação, o trabalho, a habitação, a segurança econômica e pessoal, a participação em grupos sociais e políticos, as atividades religiosas, os relacionamentos afetivos e sexuais, o acesso às instalações públicas, à liberdade de movimentação e o estilo geral da vida diária, incluindo nessa realidade o acesso à comunicação. Surge assim o reconhecimento de que pessoas "deficientes" sejam consideradas cidadãs possuidoras de direitos e obrigações, partícipes e construtoras da sociedade ${ }^{3}$.

No Brasil, as lutas dos diversos movimentos sociais organizados em prol dos direitos das pessoas portadoras de deficiência tiveram início há três

\footnotetext{
3 Ver Direitos contidos na Declaração de Direitos das Pessoas Deficientes, proclamada pela ONU em 1975.
} 
décadas, e embora já tenham obtido avanços significativos, ainda existem vários obstáculos que mantêm a exclusão desses cidadãos no sentido de uma vida independente, auto-sustentada e plena. A própria legislação brasileira até a década de 1980 mantinha um caráter assistencialista e paternalista, em que os deficientes deviam adaptar-se ao meio onde vivia e não o contrário. Atualmente a política nacional visa à integração, entendendo a inclusão no sentido amplo, envolvendo as esferas culturais, socioeconômicas e políticas (LAVALLE, 2003).

Em se tratando de definições a respeito dos portadores de deficiência, observa-se que historicamente, quem desenvolve a ação definidora são os grupos que detêm o poder. Por esta razão que resulta na visão da sociedade sobre os deficientes, sem considerar a realidade e a visão desses grupos.

Assim, as noções de saúde, doença, normalidade e anormalidade, eficiência e deficiência, são construções histórico-sociais, e a palavra deficiência definida pelo dicionário através da falta ou carência tem uma conotação de incapacidade, e assim a expressão "portador de deficiência" incorpora o mesmo sentido. Os portadores de deficiências acabam sendo vítimas de estereótipos e discriminações por desviarem do padrão de normalidade dos seres humanos.

Para destacar a possibilidade de inclusão dessas pessoas, Oliveira (1999) adotou a escrita da palavra "deficiência" com uma alteração simbólica dEficiência - de forma a destacar a ambigüidade do termo. Em seu trabalho, a autora procurou confirmar a hipótese de o "deficiente" poder ser eficiente, concorrendo em iguais condições com pessoas "normais", desde que consideradas suas diferenças.

Para Santos (2003), o universalismo que queremos hoje é aquele que tenha como ponto em comum a dignidade humana. A partir daí, surgem muitas diferenças que devem ser respeitadas. Temos direito de ser iguais quando a diferença nos inferioriza e direito de ser diferentes quando a igualdade nos descaracteriza. 

cidadania e Turismo: uma investigação sobre a existência de serviços adaptados às pessoas com necessidades especiais nos meios de hospedagem da região metropolitana de Curitiba. Revista Brasileira de

Percebe-se a inexistência de um consenso sobre os termos utilizados para a identificação do deficiente visual (e também do deficiente auditivo). Nem todos os indivíduos incluídos nessa categoria se identificam com os termos "portador de deficiência visual, deficiente visual, ou deficiente auditivo". A expressão "surdo", por exemplo, é como melhor os próprios se identificam e identificam seus pares (SÁ, 2002).

Quando se trata da cidadania para as pessoas com necessidades especiais, entende-se como complemento na idéia de inclusão social as questões culturais, a inclusão formal-legal, a inclusão socioeconômica (educação e formação profissional), o mercado de trabalho e a inclusão política e civil.

A falta ou redução de um dos sentidos não é e não pode ser o principal obstáculo para a inclusão dos portadores de deficiência como cidadãos, plenos de direitos e deveres. Quando Ihes forem oferecidas às condições de aprendizado e os meios de desenvolver e aplicar suas habilidades, haverá consequentemente as condições de participação na vida social, econômica, cultural e política da sociedade.

Contudo, no contexto brasileiro, marcado pela forte desigualdade social, os avanços obtidos pelos deficientes visuais, nos últimos anos, permanecem cerceados pela máxima da inclusão para quem tem mais condições (físicas, sociais e econômicas) e da exclusão para quem tem menos, ou não tem essas condições.

\section{Turismo e acessibilidade}

A Política Nacional para Integração da Pessoa Portadora de Deficiência $(\mathrm{PPD})^{4}$ conceitua:

Considera-se pessoa portadora de deficiência aquela que apresenta, em caráter permanente, perdas ou anormalidades de sua estrutura ou função psicológica, fisiológica ou anatômica, que

\footnotetext{
${ }^{4}$ Decreto 914, 06/09/1993, artigo 30

(http://www.camara.gov.br/internet/infdoc/Publicacoes/html/pdf/LegPortDefinal.pdf)
} 
ALMEIDA, Wolney Gomes; KUSHANO, Elizabete Sayuri. Inclusão social, cidadania e Turismo: uma investigação sobre a existência de serviços adaptados às pessoas com necessidades especiais nos meios de hospedagem da região metropolitana de Curitiba. Revista Brasileira de Pesquisa em Turismo. v. 2, n. 4, p. 88-101, dez. 2008.

gerem incapacidade para o desempenho de atividade, dentro do padrão considerado normal para o ser humano.

O turismo inclusivo visa oportunizar a todas as pessoas a participação e acesso em atividades comuns e não em grupos isolados (guetos). Nesse sentido, o Art. $2^{\circ}$ do Código Mundial de Ética do Turismo diz que as atividades turísticas devem respeitar a igualdade entre homens e mulheres, devem tender a promover os direitos humanos e especialmente os direitos particulares de grupos, especificamente, crianças, idosos, deficientes, minorias étnicas e os povos autóctones.

Segundo os dados da Society for Acessible Travel and Hospitality - SATH, nos Estados Unidos da América são 39 milhões de portadores de necessidades especiais, no Canadá 4,2 milhões, no Brasil são 24 milhões (HENRIQUE; LIMA, 2004).

As ofertas de produtos e serviços turísticos para pessoas com necessidades especiais e mobilidade reduzida estão aumentando, inclusive no Brasil. Tal fato pode ser observado em algumas companhias aéreas brasileiras que proporcionam atendimento personalizado com equipes treinadas e orientadas para PPD. Cadeiras de rodas especiais, cartilhas de emergência em braile, entre outras adaptações, são encontradas. Porém, a falta de intérpretes em linguagem libras, a ausência de sinalização em braile e a falta de informação adequada nos atrativos e infra-estrutura de apoio turístico abalizam as barreiras comunicacionais. Há que se observar, também, que os equipamentos turísticos não contemplam as limitações físicas e psíquicas de PPD proporcionando total dependência (HENRIQUE; LIMA, 2004).

O Ministério do Turismo produziu o documento "Turismo e Acessibilidade", a partir do "Manual de Recepção e Acessibilidade de Pessoas com Deficiência a Empreendimentos e Equipamentos Turísticos" publicado pela Embratur em 2001, bem como de acordo com a legislação brasileira e Normas Técnicas - ABNT. Em tal documento há muitas informações pertinentes, como as contidas no capítulo 6, que cita uma série de orientações para bem atender as pessoas com deficiência auditiva, visual, mental, dentre outras. 
O Decreto no 3.298, de 20/12/1999, publicado em 21/12/1999, que regulamentou a Lei no 7.853, de 24 de outubro de 1989, dispõe sobre a Política Nacional para a Integração da Pessoa Portadora de Deficiência e consolida as normas de proteção. Tais normas asseguram à pessoa portadora de deficiência o pleno exercício de seus direitos, conforme o Art. 20: à educação, à saúde, ao trabalho, ao desporto, ao turismo, ao lazer, à previdência social, à assistência social, ao transporte, à edificação pública, à habitação, à cultura, ao amparo à infância e à maternidade, e de outros que decorrentes da Constituição e das leis, propiciem seu bem-estar pessoal, social e econômico (BRASIL, 1989).

Em se tratando de grupos específicos, tais como os surdos, uma pesquisa revela que entre os 5,7 milhões de brasileiros com deficiência auditiva, 176.067 são incapazes de ouvir. "A comunidade surda continua lutando pelo exercício da cidadania e de respeito à sua cultura e identidade frente ao oralismo", comenta Skilar (1998).

Uma pesquisa realizada em Ponta Grossa (PR) constata os problemas que os surdos enfrentam enquanto turistas. Ponta Grossa tem 4 mil surdos. Conforme questionário aplicado na Escola Municipal para surdos Geny de Jesus Souza Ribas e na Associação dos Surdos de Ponta Grossa, a maioria dos surdos deixa de viajar, principalmente pela falta de comunicação que os impede, por exemplo, de comprar um pacote de viagem ou mesmo efetuar uma reserva num hotel. Não há intérpretes de libras nos hotéis, aeroportos, rodoviárias, restaurantes e atrativos naturais e culturais pontagrossenses (ROMANI; MOREIRA, 2004).

Nesse sentido, instiga-se o trade turístico a ampliar além das línguas estrangeiras sua forma eficiente de comunicação. Por que não aprender a linguagem dos sinais?

No dia 02 de julho de 2007, iniciou-se em Belo Horizonte, por meio da Belotur, órgão municipal de turismo, um curso básico de língua brasileira de sinais - Libras, com o objetivo de capacitar funcionários dos postos de informações turísticas para o atendimento às pessoas com necessidades 
especiais sensoriais e com dificuldades de comunicação. O curso tem um carga horária de 40 horas e pretende qualificar Belo Horizonte como a primeira cidade brasileira com atendentes em postos de informações turísticas que conheçam a linguagem de sinais (BELOTUR).

Além da importância ética, as empresas responsáveis ganham em credibilidade e fortalecem sua imagem junto aos consumidores. Como salientado na publicação "O que as Empresas podem fazer pela Inclusão das Pessoas com Deficiência" do Instituo Ethos (2002, p.19):

As empresas têm uma grande capacidade de influir na transformação da sociedade. Mesmo as mudanças de caráter interno repercutem diretamente na vida dos funcionários, suas famílias e na comunidade com a qual a empresa se relaciona.

Além da motivação ética e da determinação legal, a empresa tem outro motivo relevante para adotar uma política inclusiva em relação à pessoa com deficiência: ela pode obter benefícios significativos com essa atitude. Um dos ganhos mais importantes é o de imagem.

\section{Metodologia e resultados}

Com o intuito de investigar a quantidade de unidades hoteleiras adaptadas para pessoas com necessidades especiais na Região Metropolitana de Curitiba (RMC), procedeu-se do seguinte modo: primeiramente, munidos com uma lista contendo a relação dos meios de hospedagem da RMC, cadastrados no Ministério do Turismo. Tal lista foi obtida no dia 16 de outubro de 2006 no site da Paraná Turismo - órgão oficial de Turismo do Estado do Paraná. Em seguida, foram verificados todos os empreendimentos hoteleiros que continham site oficial em funcionamento. Dos 158 meios de hospedagem cadastrados junto ao Ministério do Turismo, 111 possuem site em funcionamento. Ou seja, 47 não possuem site ou possuem site, mas não estão em funcionamento. Também foi feito contato telefônico em todos os meios de hospedagem que indicavam a existência de apartamentos para pessoas com necessidades especiais em seus sites oficiais. Foram feitas as seguintes perguntas aos recepcionistas e/ou ao setor de reservas: que tipo de adaptação 
ALMEIDA, Wolney Gomes; KUSHANO, Elizabete Sayuri. Inclusão social, cidadania e Turismo: uma investigação sobre a existência de serviços adaptados às pessoas com necessidades especiais nos meios de hospedagem da região metropolitana de Curitiba. Revista Brasileira de Pesquisa em Turismo. v. 2, n. 4, p. 88-101, dez. 2008.

ISSN: $1982-6125$

tem nas unidades habitacionais? Quantas unidades habitacionais possuem adaptação? Algum serviço e/ou adaptação para cegos e surdos? A pesquisa ocorreu entre os dias 12 a 29 de maio de 2007.

É sabido que o site eletrônico é um modo eficiente de marketing. Nele pode-se fazer um "passeio" virtual pelos lugares. Em se tratando dos meios de hospedagem, pode-se ter uma noção sobre as instalações dos apartamentos, das salas de eventos, dos restaurantes, das áreas de lazer, bem como informar-se sobre os serviços oferecidos e as tarifas praticadas.

\begin{tabular}{|c|c|c|}
\hline $\begin{array}{l}\text { Nome do meio de hospedagem e da } \\
\text { cidade em que se localiza }\end{array}$ & $\begin{array}{l}\text { Quantidade de } \\
\text { UHs adaptados }\end{array}$ & Tipo de adaptações existentes \\
\hline AltaReggia Plaza Hotel - Curitiba & 01 & UH adaptada para cadeirante. \\
\hline Blue Tree St Michel - Curitiba & 02 & $\begin{array}{l}\text { UHs adaptadas para cadeirantes e sistema braile } \\
\text { no elevador. }\end{array}$ \\
\hline $\begin{array}{l}\text { Bourbon Curitiba Hotel \& Tower - } \\
\text { Curitiba }\end{array}$ & 01 & UH adaptada para cadeirante. \\
\hline Bourbon Express Batel - Curitiba & 01 & UH adaptada para cadeirante. \\
\hline Crowne Plaza Curitiba - Curitiba & 02 & UHs adaptadas para cadeirantes. \\
\hline Grand Hotel Rayon - Curitiba & 02 & $\begin{array}{l}\text { UHs adaptadas para cadeirantes e sistema braile } \\
\text { no elevador. }\end{array}$ \\
\hline Granville Park Hotel - Curitiba & 02 & UHs adaptadas para cadeirantes. \\
\hline Holiday Inn Batel - Curitiba & 02 & UHs adaptadas para cadeirantes. \\
\hline Holiday Inn Express - Curitiba & 02 & UHs adaptadas para cadeirantes. \\
\hline Hotel Brasília - Curitiba & 01 & UH adaptada para cadeirante. \\
\hline Hotel Ibis Batel - Curitiba & 02 & $\begin{array}{l}\text { UHs adaptadas para cadeirantes e sistema braile } \\
\text { no elevador }\end{array}$ \\
\hline $\begin{array}{l}\text { Hotel Ibis Curitiba Centro Cívico - } \\
\text { Curitiba }\end{array}$ & 01 & UH adaptada para cadeirante. \\
\hline Hotel Nikko - Curitiba & 01 & UH adaptada para cadeirante. \\
\hline Hotel Paraná Suíte - Curitiba & 02 & $\begin{array}{l}\text { UHs adaptadas para cadeirantes. O único que } \\
\text { descreve o que consta em seus apartamentos } \\
\text { para deficientes físicos: persianas e frigobar } \\
\text { adaptados, suítes conjugadas para pessoas } \\
\text { acompanhadas de famílias, telefone sem fio, ar } \\
\text { condicionado com controle remoto, tomadas de } \\
\text { computador e internet, assoalho em carpete de } \\
\text { madeira, grades de proteção ao lado das camas. }\end{array}$ \\
\hline Lizon Curitiba Hotel - Curitiba & 01 & UH adaptada para cadeirante. \\
\hline Mercure Curitiba Batel - Curitiba & 02 & UHs adaptadas para cadeirantes. \\
\hline Mercure Curitiba Golden - Curitiba & 01 & UH adaptada para cadeirante. \\
\hline Mercure Apt Sete de Setembro - Curitiba & 01 & UH adaptada para cadeirante. \\
\hline Pestana Curitiba Hotel - Curitiba & 02 & Braile no elevador \\
\hline 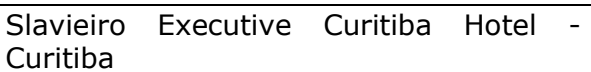 & 01 & UH adaptada para cadeirante. \\
\hline Slaviero Palace Hotel - Curitiba & 01 & UH adaptada para cadeirante. \\
\hline Slaviero Rockefeller Hotel - Curitiba & 01 & UH adaptada para cadeirante. \\
\hline $\begin{array}{l}\text { Holiday Inn Express - São José dos } \\
\text { Pinhais }\end{array}$ & 02 & UHs adaptadas para cadeirantes. \\
\hline Hotel Exclusivo - São José dos Pinhais & 01 & UH adaptada para cadeirante. \\
\hline $\begin{array}{l}\text { Ibis Curitiba Aeroporto - São José dos } \\
\text { Pinhais }\end{array}$ & 02 & UHs adaptadas para cadeirantes. \\
\hline
\end{tabular}

Quadro 1 - Meios de hospedagem que indicaram ter apartamentos adaptados para pessoas com necessidades especiais. 
Dos 111 meios de hospedagem, possuem unidades habitacionais (UHs) adaptadas, conforme indicado em seus respectivos sites e apresentados no quadro 1.

No total foram identificados 25 meios de hospedagem, sendo 22 localizados no centro da cidade de Curitiba e 3 em São José dos Pinhais. A quantidade de unidades habitacionais (UH) em Curitiba são 34 e 3 em São José dos Pinhais, totalizando 37 UHs na RMC.

Todos os meios de hospedagem identificados estão localizados em áreas centrais ou de trânsito, têm características de hotéis executivos, muitos com áreas de eventos e bussines center. Não foi identificado nenhum meio de hospedagem de lazer que possua adaptações.

A grande maioria dos meios de hospedagem é de categoria superior. Apenas o Hotel Brasília, na categoria super-econômico possui apartamento adaptado. Na categoria econômica, apenas os Hotéis Ibis da Rede Accor.

Todos os meios de hospedagem que informaram ter apartamentos adaptados para pessoas com necessidades especiais (na maioria dos sites utilizam as expressões "portadores" ou "deficientes") são direcionados para cadeirantes. Sendo que alguns desses apartamentos são preferenciais também para os idosos.

Não há nenhum serviço ou adaptação especial para os surdos. Para os cegos há alguns que têm sistema braile nos elevadores, mas tais não divulgam nos seus sites oficiais essa informação.

Os preços cobrados nas unidades adaptadas são os mesmos das consideradas padrão.

\section{Considerações finais}

Falar de inclusão social e cidadania reflete em falarmos de empresas socialmente responsáveis. Seja pelo caráter da filosofia da própria empresa, ou mesmo para cumprir determinada legislação, como também para assegurar uma boa imagem perante a sociedade, o fato é que ter produtos e serviços 

cidadania e Turismo: uma investigação sobre a existência de serviços adaptados às pessoas com necessidades especiais nos meios de hospedagem da região metropolitana de Curitiba. Revista Brasileira de

que abarquem a inclusão de pessoas com necessidades especiais está, felizmente, sendo menos incomum.

Porém, pode-se observar que os meios de hospedagem da Região Metropolitana que dizem ter apartamentos para portadores de necessidades especiais ou deficientes físicos, são $100 \%$ direcionados para os indivíduos com dificuldades de locomoção, geralmente usuários de cadeiras de rodas. Em alguns estabelecimentos, tem-se atentado para os cegos, fato demonstrado pela inclusão de leitura em braile nos elevadores. No entanto, tal ação ainda é incipiente, haja visto que muitas outras informações também poderiam estar em braile, como por exemplo, o cardápio no café da manhã, as normas do estabelecimento, entre outros.

Para os surdos o processo inclusivo tem sido ainda mais lento, sendo muito raro encontrar algum profissional capacitado para comunicação em linguagem de sinais.

O turismo acessível para todos ainda não é uma realidade. Cases de sucesso tem aumentado, demonstrando a necessidade do setor em se desenvolver e se qualificar para atender demandas específicas. Senão, do que adianta projetos e investimentos grandiosos no turismo, se ele ainda continuar elitizado e arcaico no que se refere à inclusão social e cidadania?

\section{Referências}

BAVA, Silvio Caccia. A Produção da Agenda Social Mundial: uma discussão sobre contextos e conceitos. Cadernos Gestão Pública e Cidadania, São Paulo: FGV, 2003.

BELOTUR. Turismo inclusivo: Belotur promove curso de Libras (a linguagem dos sinais). Disponível em < http://www.turismoresponsavel.tur.br $>$. Acesso em: 13 de julho de 2007.

BRASIL. Presidência da República - Casa Civil: subchefia para assuntos jurídicos. Lei n. 7853 de 24 de Outubro de 1989. Disponível em: $<$ http://www.planalto.gov.br/ccivil 03/LEIS/L7853.htm>. Acesso em: 05 de junho de 2007. 

cidadania e Turismo: uma investigação sobre a existência de serviços adaptados às pessoas com necessidades especiais nos meios de hospedagem da região metropolitana de Curitiba. Revista Brasileira de

HENRIQUE, Humberto de Lima; LIMA, Iane Sampaio Moreira. Responsabilidade Social do turismo na inclusão da pessoa portadora de deficiência ou com mobilidade reduzida. In: BAHL, Miguel (Org.). Turismo com responsabilidade social. Congresso Brasileiro de Turismo. São Paulo: Roca, 2004.

INSTITUTO ETHOS. O que as empresas podem fazer para a Inclusão das Pessoas com Deficiência. São Paulo, maio de 2002. Disponível em: < http://www.uniethos.org.br>. Acesso em: 04 de junho de 2007.

LAVALLE, Adrián Gurza. Cidadania, igualdade e diferença. Lua Nova, n. 59, p.75-93, 2003.

ONU. Programa de ação mundial para as pessoas com deficiência - Resolução 37/52 de 03 de dezembro de 1982 - Assembléia Geral da Organização das Nações Unidas - ONU.

ROMANI, Graziela; MOREIRA, Jasmine Cardozo. Integração social: surdos, profissionais de turismo e aprendizado da língua de sinais. In: BAHL, Miguel (Org.). Turismo com responsabilidade social. Congresso Brasileiro de Turismo. São Paulo: Roca, 2004.

SÁ, Nidia Regina Limeira de. Cultura, poder e educação de surdos. Manaus: EDUA, 2002.

SANTOS, Tania. Globalização e exclusão: a dialética da mundialização do capital. Sociologias, Porto Alegre, n.6, ju-dez. 2001. Disponível em: <http://www.scielo.br> Acesso em: 13 de maio de 2007.

SASSAKI, Romeu Kazumi. Inclusão: Construindo uma sociedade para todos. Rio de Janeiro: WVA, 1997.

SKILAR, C. (org.). A surdez: um olhar sobre as diferenças. Porto Alegre: Mediações, 1999.

\section{Bibliografia}

SECRETARIA DE ESTADO DO TURISMO - SETU. Empresas, Empreendimentos e Serviços Turísticos. Disponível em: < http://www.pr.gov.br/turismo/empresas.shtml?profissionais >. Acesso em: 05 de maio de 2007. 